\title{
THE GENETICS OF PLATE MORPHS IN FRESHWATER THREESPINE STICKLEBACKS
}

\author{
D. W. HAGEN* and L. G. GILBERTSON \\ College of Fisheries, University of Washington, Seattle, Washington 98195
}

Received 17.viii.72

\begin{abstract}
SUMMARY
The simplest model that accounts for segregation of the low, partial, and complete morphs in sticklebacks is one with two autosomal loci, each with two alleles, and having the relationships between genotype and phenotype as shown in fig. 2. There is no strong evidence for linkage, but this and the modification of dominance are suggested by the data. A distinct phenotype, called minute keel, is present in Lake Wapato at a low frequency. Further data are necessary, but it seems to be multifactorially inherited and under partial control by the female parent.
\end{abstract}

\section{INTRODUGTION}

FreshwATER populations of the threespine stickleback (Gasterosteus aculeatus) are highly variable for the number of bony plates on the sides of the body. Some of the variability is maintained by hybridisation between marine and freshwater populations (Heuts, 1947a; Munzing, 1963, 1972; Penczak, 1965; Paepke, 1970), but in the Pacific Northwest of America hybridisation is largely confined to narrow zones in coastal streams and apparently introgression does not occur (Heuts, 1947a, b; Hagen, 1967; Hagen and McPhail, 1970; Hagen and Gilbertson, 1972). This variability is however strongly influenced by natural selection (Heuts, 1947b, 1956; Hagen and McPhail, 1970; Hagen and Gilbertson, 1972, 1973; Moodie, 1972a, b; Moodie, McPhail and Hagen, 1973).

Since the adaptive and evolutionary significance of lateral plates is the subject of active research the genetics should be known. The purpose of this paper is to present data from our breeding programme on the genetics of three plate morphs that occur in permanent freshwater sticklebacks.

\section{Materials AND MEthods}

The three morphs considered in this paper are the low plated which has anterior plates only, the partially plated which has anterior plates plus a caudal keel of plates, and the completely plated which has a continuous series of bony plates along the sides of the body (fig. 1). Freshwater populations may be monomorphic for any of these, they may be polymorphic with all three present, or with only the lows and partials present (Hagen and Gilbertson, 1972 and unpublished data). It is strange that populations with only partials and completes are unknown. The number of plates within each morph varies widely and this variation has a high heritability (Hagen, 1973).

* Present address: Biology Department, University of New Brunswick, Fredericton, New Brunswick, Canada. 
Progeny reared in the laboratory always segregate sharply for the three morphs and so can be scored unambigously. In the field we have rarely found individuals that could belong to either the partial or the complete morph. These have a gap about the width of a missing plate, usually near the posterior but before the keel. Crosses between such fish in the laboratory, however, segregate as complete morphs. Fish with a symmetrical gap on each side about the width of two missing plates (or more) always segregate as partials.

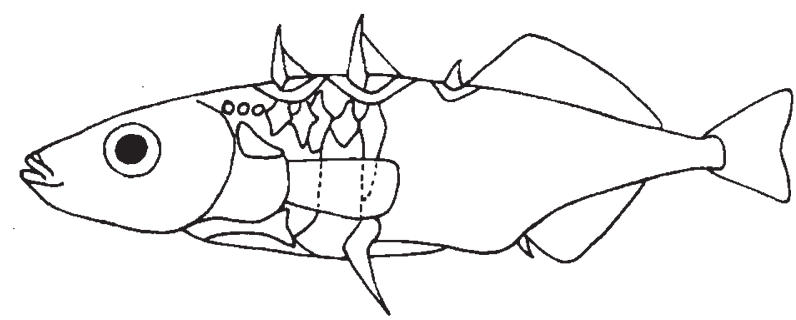

LOW PLATED MORPH

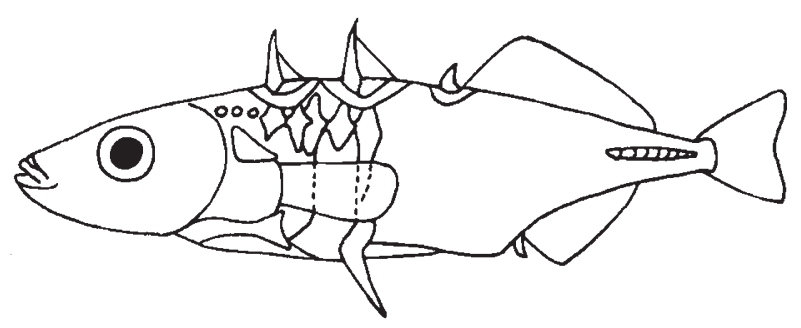

PARTIALLY PLATED MORPH

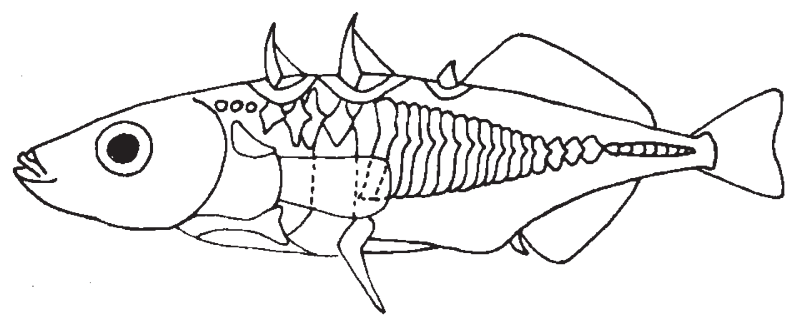

COMPLETELY PLATED MORPH

FIG. 1.-Three plate morphs occurring in permanent freshwater sticklebacks. Bony plates are shown on the body sides.

These laboratory crosses are consistent with observations on large samples from monomorphic wild populations in which completes never have a symmetrical gap greater than the width of one plate, whereas partials have a symmetrical gap the width of at least two plates but usually more. Phenocopies of the morphs have not been reported, and offspring reared in the laboratory with parents from monomorphic populations (table 1; and Hagen, 1973) give no evidence they exist.

Most of the parents for the crosses were gathered at Lake Wapato, where all three morphs occur, but smaller numbers of crosses were made with parents 
from several monomorphic populations in Washington State. Some crosses with the marine stickleback (trachurus), which is completely plated, were also made. With the exception of the latter all are permanent freshwater sticklebacks; details on these populations and their morph frequencies are given by Hagen and Gilbertson (1972, 1973).

Progeny were uniformly reared in the laboratory. The methods for rearing progeny and making crosses follow Hagen (1973) with but two exceptions. First, all progeny were reared at room temperature $\left(19^{\circ} \mathrm{C} . \pm 2^{\circ}\right)$. Second, in the previous paper half of each clutch of eggs was discarded, but here whole clutches were always used. To prevent high mortality from excess crowding in one aquarium, clutches greater than 30 were always split such that numbers of offspring in one aquarium never exceeded 30 .

TABLE 1

Segregation of plate morphs in male and female progeny obtained with parents from monomorphic populations

\begin{tabular}{|c|c|c|c|c|c|c|c|c|c|c|c|c|c|}
\hline \multirow{2}{*}{\multicolumn{2}{|c|}{ rood No. }} & \multicolumn{2}{|c|}{$\begin{array}{l}\text { Parents and } \\
\text { provenance }\end{array}$} & \multicolumn{3}{|c|}{ Progeny } & & & \multicolumn{2}{|c|}{$\begin{array}{l}\text { Parents and } \\
\text { provenance }\end{array}$} & \multicolumn{3}{|c|}{ Progeny } \\
\hline & & $\sigma^{*}$ & ㅇ & s & & $q$ & \multicolumn{2}{|c|}{ Brood No. } & $0^{*}$ & $q$ & $\sigma^{x}$ & & \\
\hline 1 & $\mathbf{F}_{1}$ & $T(S)$ & $\mathbf{T}(\mathbf{S})$ & 23 & $\mathrm{~T}$ & 31 & 13 & $F_{1}$ & $\mathrm{C}(\mathrm{V})$ & $L(C)$ & 44 & $\mathbf{P}$ & 36 \\
\hline 2 & $\mathbf{F}_{1}$ & $T(S)$ & $\mathbf{T}(\mathbf{S})$ & 34 & $\mathbf{T}$ & 29 & 14 & $F_{1}$ & $\mathbf{L}(\mathrm{C})$ & $\mathrm{C}(\mathrm{V})$ & 16 & $\mathbf{P}$ & 22 \\
\hline 3 & $F_{1}$ & $\mathrm{C}(\mathrm{V})$ & $\mathrm{C}(\mathrm{V})$ & 21 & C & 19 & 15 & $F_{1}$ & $\mathrm{C}(\mathrm{V})$ & $\mathbf{L}(\mathrm{S} s)$ & 17 & C & 25 \\
\hline 4 & $\mathbf{F}_{1}$ & $\mathrm{C}(\mathrm{V})$ & $\mathrm{C}(\mathrm{V})$ & 29 & C & 26 & 16 & $\mathbf{F}_{1}$ & $\mathrm{~L}(\mathrm{Sc})$ & $\mathrm{C}(\mathrm{V})$ & 16 & C & 23 \\
\hline 5 & $F_{1}$ & $\mathbf{L}(\mathrm{Sq})$ & $\mathbf{L}(\mathrm{Sq})$ & 17 & $\mathbf{L}$ & 15 & 11 & $F_{2}$ & $\mathbf{P}$ & $\mathbf{P}$ & 4 & $\mathbf{L}$ & 6 \\
\hline 6 & $F_{1}$ & $L(C)$ & $\mathbf{L}(\mathbf{C})$ & 24 & $\mathbf{L}$ & 27 & & & & & $\begin{array}{r}10 \\
5\end{array}$ & $\begin{array}{l}\mathbf{P} \\
\mathbf{C}\end{array}$ & 9 \\
\hline 7 & $F_{1}$ & $P(Q)$ & $P(Q)$ & 18 & $\mathbf{P}$ & 14 & 12 & $F_{0}$ & $\mathbf{P}$ & $\mathbf{P}$ & 6 & L & \\
\hline 8 & $F_{1}$ & $\mathbf{P}(\mathbf{Q})$ & $\mathbf{P}(\mathbf{Q})$ & 28 & $\mathbf{P}$ & 34 & 12 & $F_{2}$ & $\mathbf{F}$ & $\mathbf{r}$ & 11 & $\mathbf{P}$ & 16 \\
\hline 9 & $\mathbf{F}_{1}$ & $\mathbf{P}(\mathbf{Q})$ & $\mathbf{P}(\mathbf{Q})$ & 19 & $\mathbf{P}$ & 30 & & & & & 8 & C & a \\
\hline 0 & $\mathbf{F}_{1}$ & $\mathbf{P}(\mathbf{Q})$ & $\mathbf{P}(\mathbf{Q})$ & 21 & $\mathbf{P}$ & 28 & 14 & $F_{8}$ & $\mathbf{P}$ & $\mathbf{P}$ & & L & 10 \\
\hline 11 & $\mathbf{F}_{1}$ & $\mathrm{C}(\mathrm{V})$ & $\mathbf{L}(\mathbf{S q})$ & 14 & $\mathbf{P}$ & 12 & & & & & $\begin{array}{l}23 \\
12\end{array}$ & $\begin{array}{l}\mathbf{P} \\
\mathbf{C}\end{array}$ & $\begin{array}{r}22 \\
7\end{array}$ \\
\hline 2 & $\mathbf{F}_{1}$ & $L(S q)$ & $\mathbf{C}(\mathbf{V})$ & 23 & $\mathbf{P}$ & 20 & & & & & & & \\
\hline
\end{tabular}

The morphs: $\mathrm{T}$ (trachurus), $\mathrm{C}$ (complete), $\mathrm{P}$ (partial), $\mathrm{L}$ (low). Localities shown in parentheses: $\mathrm{S}=$ Samish River; $\mathrm{V}=$ Vancouver Creek; $\mathrm{Sq}=$ Squalicum Creek; $\mathrm{C}=$ Conner Creek; $\mathrm{Q}=$ Quinault Lake; $\mathrm{Sc}=$ Scatter Creek.

For the stocks used here plates are fully formed at a size of at least $28 \mathrm{~mm}$. (Hagen, 1973) and all the progeny we scored were at least $30 \mathrm{~mm}$., but most were adults.

\section{ANAlysis AND DisGUSsion}

The uniformly reared offspring obtained with parents from monomorphic populations, and with trachurus, show that the morphs are genetically controlled (table 1). It is not known which sex in sticklebacks is heterogametic, but whichever, both sexes of offspring from reciprocal crosses between the monomorphic populations belong to the same morph (table 1). Thus the trait cannot be sex-linked. Crosses between morphs from the polymorphic populations (table 2) and the segregation of the morphs between sexes confirm the fact that the morphs are genetically controlled and autosomally inherited. 
might then suppose that the morphs are controlled by one locus with two alleles such that the partials are the heterozygote. But crosses between lows and completes also give all completely plated progeny (table 1). Also, if the morphs were controlled by two alleles, monomorphic populations of partials could not exist as they do. It might be argued that a balanced lethal system occurs in such populations, but this can be excluded as the combined mortality of eggs and offspring from Lake Quinault (table 1) is less than 6 per cent. Furthermore, with two alleles crosses between partials should segregate for all three morphs ( $1: 2: 1$ ratio) which is often not so (table 2), and it would be impossible to obtain segregation from crosses between lows or completes which does occur (table 2). Clearly, a model with two alleles at a locus is completely rejected by the data.

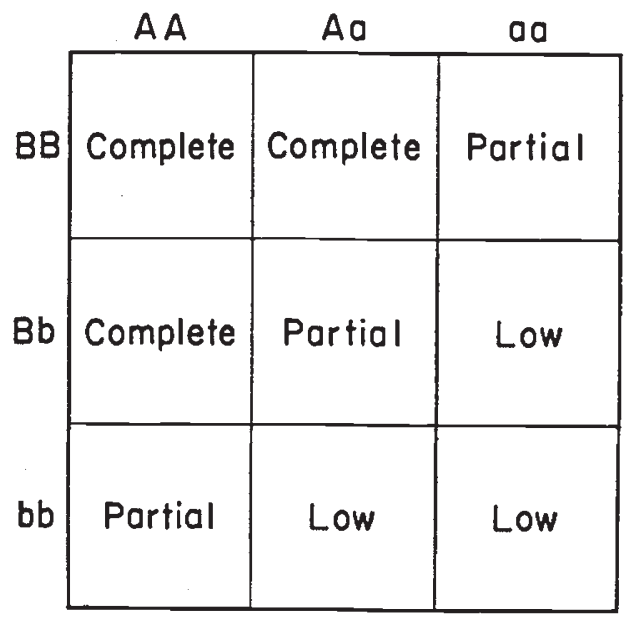

Fig. 2.-The relationships between genotypes and phenotypes for the three plate morphs of sticklebacks. The two loci are represented as $\mathbf{A}$ and $\mathbf{B}$.

Neither can the data be explained by assuming three alleles. With this model crosses between partials could not segregate for lows and partials, but this is a frequently verified result (table 2).

The segregation and dominance relationships among the morphs is therefore complex. All the morphs can exist as monomorphic populations that breed true in the laboratory, and crosses between like morphs from polymorphic populations can segregate. The simplest model we can construct to explain the results is one with two loci, each with two alleles, and having the relationships between genotype and phenotype as shown in fig. 2. By the model we can account for the existence of monomorphic populations of all the morphs, and for the segregation and dominance relationships among them. There is however a difficulty in obtaining a goodness-of-fit for the data to the model. With crosses between any of the morphs it is possible to obtain several segregations (fig. 2). For example, with crosses between partials we may obtain by the model all partial progeny; completes, partials, and lows with a $1: 2: 1$ ratio; or a 5:6:5 ratio. When testing the data for a family by chi-square, which of the possible segregations do we take as an expected value? It is clearly not valid to use as the expected the ratio most like that observed for we are then introducing a bias that 
consistently favours the model. This difficulty in fitting two-locus models has apparently not been solved. We are indebted to Dr Joseph Felsenstein who has developed a likelihood ratio test for us that allows an unbiased fit. Only a brief account is given here.

The test involves calculating the likelihood

$$
L=\prod_{m} \sum_{j=1}^{J} x_{i_{m} j} \prod_{k} \theta_{i_{m} j k n_{m k}},
$$

where $m$ is an index running over all families, $i_{m}$ is the "mating type" of $m$ th family, $x_{i j}$ is the probability that a family of mating type $i$ will segregate

TABLE 3

All possible genotypes for matings between partial and low morphs, and the expected proportions of low $(L)$, partial $(P)$, and complete $(C)$ offspring from these matings

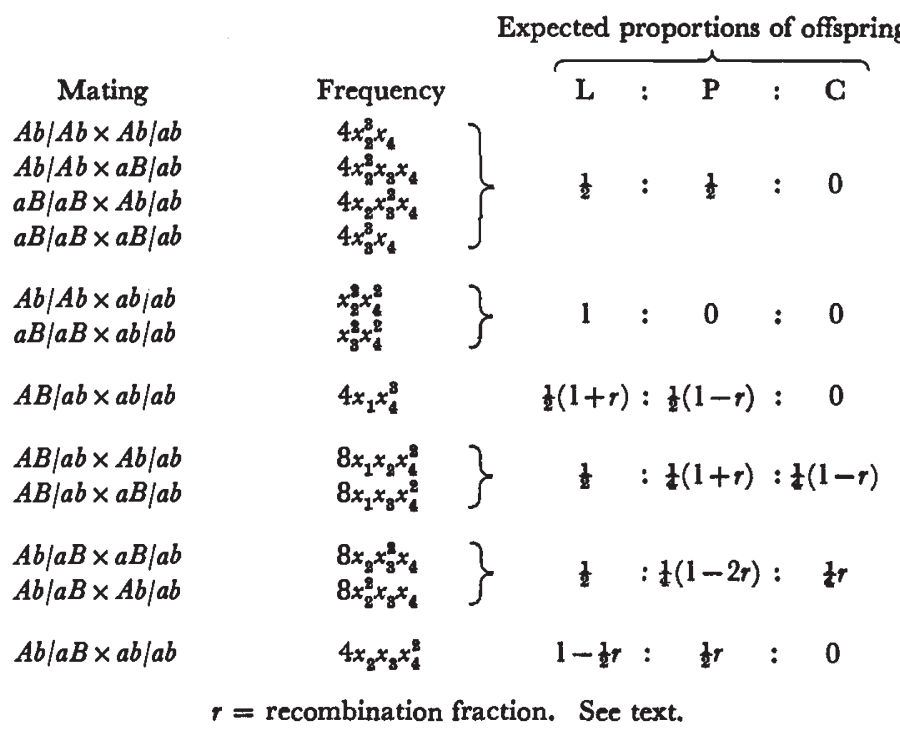

according to the $j$ th Mendelian pattern, $\theta_{i j k}$ is the probability that a random offspring of a mating of type $i$, having expected segregation pattern $j$, is of phenotype $k$, and $n_{m k}$ is the number of offspring of phenotype $k$ in the family $m$. We calculate this likelihood for the proposed model, and also a maximum likelihood for a more general set of models. The test is to look up $-2 \log _{e}\left(L_{0} / L_{1}\right)$ on a chi-square table with an appropriate number of degrees of freedom. The $x_{i j}$ and $\theta_{i j k}$ are specified by the hypothesis when calculating $L_{0}$, and are allowed to vary arbitrarily when calculating $L_{1}$. Also, the number of segregation patterns assumed, $\mathcal{F}$, is allowed to vary in finding the maximum value of $L_{1}$. The likelihoods $L_{1}$ can be found separately for each type of family. Finding them involves a rather time-consuming set of iterations by computer. A brief description of some of the problems involved will be given by Felsenstein and Patil (paper in preparation).

The values $x_{i j}$ and $\theta_{i j k}$ used in calculating $L_{0}$ are partly specified by the model, but the $x_{i j}$ depend on the gamete frequencies in the wild population, and the $\theta_{i j k}$ depend on the recombination fraction, $r$. If the frequencies of 
the gametes $A B, A b, a B$ and $a b$ are respectively $x_{1}, x_{2}, x_{3}$ and $x_{4}$, the situation for Partial $\times$ Low is shown in table 3 as an example. Each row of the table shows one possible genotypic combination in which the parents are partial and low, the frequency of that combination among random matings in a wild population, and the resulting segregation probabilities $\theta_{i j k}$. The $x_{i j}$ are calculated by dividing the mating frequencies by their sum, so that

$$
\sum_{j} x_{i j}=1 \text {. }
$$

The values $x_{1}, x_{2}, x_{3}$ and $r$ were estimated by finding those values which maximised $\mathrm{L}_{0}$. However, additional information on $x_{1}, x_{2}, x_{3}$ was available in the form of a sample of 4392 adult individuals from Lake Wapato. This sample was included in the analysis (using families from Lake Wapato only) by counting it as a large family of a new type, whose expected proportions of offspring were

$$
\begin{array}{ll}
C & x_{1}\left(x_{1}+2 x_{2}+2 x_{3}\right) \\
P & x_{2}^{2}+x_{3}^{2}+2 x_{2} x_{3}+2 x_{1} x_{4} \\
L & x_{4}\left(x_{4}+2 x_{2}+2 x_{3}\right) .
\end{array}
$$

The maximum likelihood estimates were

$\begin{array}{rr}A B & 0.0097 \\ A b & 0.0775 \\ a B & 0.0775 \\ a b & 0.8353 \\ \text { and } r= & 0.373 .\end{array}$

The likelihood was only slightly decreased if $r$ was made to be one-half, so we have no strong evidence for linkage of the two genes.

The best general model which could be found had 47 parameters. Since we have estimated 4 parameters from the data in fitting this particular twolocus model, the final test is made with $47-4=43$ degrees of freedom. The value of $\chi^{2}$ was $55 \cdot 7$, giving $0 \cdot 1>P>0 \cdot 05$. The model does therefore give an adequate fit to the data.

Four families of the second generation have been obtained in the laboratory as a further test of the model (table 4). The complete morphs obtained from family 31 (table 2) must be single heterozygotes. One of these when crossed to a partial from a monomorphic population (Quinault) segregated for completes and partials with a 1:1 ratio as we would expect by the model (table $4 ; 31 F_{2}$ ). The low progeny in family 23 must all be single heterozygotes, and should thus segregate for lows and partials with a 1:1 ratio when crossed to partials from Lake Quinault, which they do (table 4; $23 \mathrm{~F}_{2}$ ). The low progeny obtained from families 52 to 77 (table 2) must all be double homozygotes. As expected by the model, they give all lows (single heterozygotes) when crossed to partials from Quinault (crosses $54 \mathrm{~F}_{2}$ and $61 \mathrm{~F}_{2}$, table 4 ).

The only results not consistent with the model are two of the crosses between monomorphic populations of completes and lows that produced all completely plated progeny (table 1; families 15 and 16). Although the 81/1-F 
TABLE 4

Second generation offspring reared in the laboratory

$\begin{array}{cccc}\text { Brood No. } & \overbrace{0}^{\text {Parents and }} \\ 31 \mathrm{~F}_{3} & \mathrm{C}(\mathrm{W}) & \begin{array}{c}\mathrm{P}(\mathrm{Q}) \\ \text { provenance }\end{array} & \begin{array}{c}\text { Progeny } \\ 23 \mathrm{P} \\ 18 \mathrm{C}\end{array} \\ 23 \mathrm{~F}_{2} & \mathrm{~L}(\mathrm{~W}) & \mathrm{P}(\mathrm{Q}) & 29 \mathrm{~L} \\ & & & 36 \mathrm{P} \\ 54 \mathrm{~F}_{2} & \mathrm{~L}(\mathrm{~W}) & \mathrm{P}(\mathrm{Q}) & 42 \mathrm{~L} \\ 61 \mathrm{~F}_{8} & \mathrm{P}(\mathrm{Q}) & \mathrm{L}(\mathrm{W}) & 57 \mathrm{~L}\end{array}$

See table 1 for symbols.

progeny are completely plated, the individual plates are unusually small such that only a narrow series (with respect to body-depth) occurs along the sides. These unusual families could be explained by assuming a modification of dominance between the particular populations with the complete morph showing dominance (or we should say incomplete dominance as the size and width of plates is reduced). More data are required to clarify the results.

The plates of the caudal keel are usually distinct with each plate flattened dorso-ventrally and extending laterally from the side. The number of plates in the keel varies from five to eight. In Lake Wapato, however, there is a distinct phenotype that has only one or two plates in the keel and these are about half the usual size. Also, the plates are not flattened and so do not extend from the sides. These phenotypes, called minute keels, are at a frequency of about 4 per cent. in the lake. The limited data we have (table 5) suggest the inheritance is complex, probably multifactorial, and apparently it is maternally influenced since the trait segregates significantly more often in female than in male offspring $(P<0.05)$.

The three plate morphs in sticklebacks can thus be explained by a model with two unlinked, autosomal loci, each with two alleles. However, more crosses between monomorphic populations are necessary to clarify the dominance relationships with respect to the modification of dominance. And

TABLE 5

Offspring obtained with parents from Lake Wapato with and without minute keels (M.K.)

\begin{tabular}{|c|c|c|c|c|c|c|c|c|c|}
\hline \multicolumn{2}{|c|}{ Parents } & \multicolumn{3}{|c|}{ Offspring } & \multicolumn{2}{|c|}{ Parents } & \multicolumn{3}{|c|}{ Offspring } \\
\hline t & q & d & & $q$ & a & q & d & & 우 \\
\hline L & L & $\begin{array}{r}11 \\
5\end{array}$ & $\begin{array}{l}\text { L } \\
\text { M.K. }\end{array}$ & $\begin{array}{r}27 \\
4\end{array}$ & L & L & $\begin{array}{r}20 \\
1\end{array}$ & $\begin{array}{l}\text { L } \\
\text { M.K. }\end{array}$ & $\begin{array}{l}14 \\
15\end{array}$ \\
\hline L & L & $\begin{array}{r}22 \\
8\end{array}$ & $\begin{array}{l}\text { L } \\
\text { M.K. }\end{array}$ & $\begin{array}{l}15 \\
11\end{array}$ & L & M.K. & $\begin{array}{r}17 \\
6\end{array}$ & $\begin{array}{l}\text { L } \\
\text { M.K. }\end{array}$ & $\begin{array}{r}14 \\
4\end{array}$ \\
\hline L & L & $\begin{array}{r}24 \\
0\end{array}$ & $\begin{array}{l}\text { L } \\
\text { M.K. }\end{array}$ & $\begin{array}{r}31 \\
5\end{array}$ & M.K. & L & $\begin{array}{r}10 \\
9\end{array}$ & $\begin{array}{l}\text { L } \\
\text { M.K. }\end{array}$ & $\begin{array}{l}17 \\
10\end{array}$ \\
\hline L & L & $\begin{array}{r}20 \\
7\end{array}$ & $\begin{array}{l}\text { L } \\
\text { M.K. }\end{array}$ & $\begin{array}{r}13 \\
6\end{array}$ & M.K. & M.K. & $\begin{array}{l}14 \\
12\end{array}$ & $\begin{array}{l}\text { L.R. } \\
\text { M.K. }\end{array}$ & $\begin{array}{r}7 \\
16\end{array}$ \\
\hline
\end{tabular}


although we have no strong evidence for linkage, our results may be taken to suggest interaction between the two loci, and so the linkage relationships between loci should be investigated in polymorphic populations. We can see then that the inheritance of lateral plates is intricate. The three plate morphs are determined by the segregation of major genes; but the number of plates in each morph varies greatly and this quantitative variation in number results from the segregation of polygenes and has a high heritability from 0.5 to 0.84 (Hagen, 1973).

In the Pacific Northwest of America, populations may be monomorphic for any of the three morphs, or they may be polymorphic (Hagen and Gilbertson, 1972). The historical, distributional and survival data (offspring to adult) indicate that morph frequencies are controlled by strong selection, often as a balanced polymorphism (Hagen and Gilbertson, 1972; unpublished data of Hagen, Moodie and Gilbertson). There are, however, no clues as yet concerning the selective agents responsible for this variation in morph frequency. On the other hand, there is now strong evidence about the selective agents acting upon the quantitative variation in plate number, and at least one of these is selective predation by predatory fish (Hagen and Gilbertson, 1972, 1973; Moodie, 1972a, b; Moodie, McPhail and Hagen, 1973).

Acknowledgments. - We are indeb ted to Dr Joseph Felsenstein for developing the likelihood ratio test for us, and obtaining the fit of our data to the model. We wholeheartedly thank him for very helpful discussion. The research was supported by a grant from the National Science Foundation to D. W. H. (G.B. 7686) and by a grant to Dr J. Felsenstein (Task Agreement No. 5 of United States Atomic Energy Commission contract AT (45-1) 2225).

\section{REFERENCES}

HAGEN, D. w. 1967. Isolating mechanisms in threespine sticklebacks (Gasterosteus). F. Fish. Res. Bd. Canada, 24, 1637-1692.

HAGEN, D. W., AND MGPHArL, J. D. 1970. The species problem within Gasterostetus aculeatus on the Pacific Coast of North America. 7. Fish. Res. Bd. Canada, 27, 147-155.

HAGEN, D. W., AND GILBERTSON, L. G. 1972. Geographic variation and environmental selection in Gasterosteus aculeatus L. in the Pacific Northwest, America. Evolution, 26, $32-51$.

HAGEN, D. W., AND GILBERTSON, L. G. 1973. Selective predation and the intensity of selection acting upon the lateral plates of threespine sticklebacks. Heredity, 30, 273-288.

HAGEN, D. w. 1973. Inheritance of numbers of lateral plates and gill rakers in Gasterosteus aculeatus. Heredity, 30, 303-312.

HEUTs, M. J. 1947a. The phenotypic variability of Gasterosteus aculeatus (L.) populations in Belgium. Meded. Kon. VI Akad. Wetensch, 25, 5-63.

HEUTs, M. J. 1947b. Experimental studies on adaptive evolution in Gasterosteus aculeatus L. Evolution, 1, 89-102.

неUтs, м. J. 1956. Temperature adaptation in Gasterosteus aculeatus L. Publ. della Stazione Zool. die Napoli, 28, 44-61.

MoodIr, G. E. E. 1972a. Predation, natural selection and adaptation in an unusual threespine stickleback. Heredity, 28, 155-167.

Moodre, G. в. в. 1972b. Morphology, life history, and ecology of an unusual stickleback (Gasterosteus aculeatus) in the Qucen Charlotte Islands, Canada. Can. J. Zool., 50, 721. 732.

MOODIE, G. E. E., MCPHAI, J. D., AND HAGEN, D. W. 1973. Experimental demonstration of selective predation on Gasterosteus aculeatus. Behaviour, in press.

Munzing, J. 1963. The evolution of variation and distributional patterns in European populations of the threespine stickleback, Gasterosteus aculeatus. Evolution, 17, 320-332. 
munzing, J. 1972. Polymorphe populationen von Gasterosteus aculeatus L. (Pisces, Gasterosteidae) in sekundären intergradationszonen der Deutschen Bucht und benachbarter Gebiete. Faun. Okol. Mitt., 4, 69-84.

PAEPKE, H. 1970. Studien zur Okologie, variabilitat und populationsstruktur des Dreistachligen und Neunstachligen Stichlings. Veroff. Bez-Mus. Potsdam, 21, 5-48.

PENCZAK, T. 1965. Morphological variation of the stickleback (Gasterosteus aculeatus) in Poland. Zool. Poloniae, 15, 3-49. 